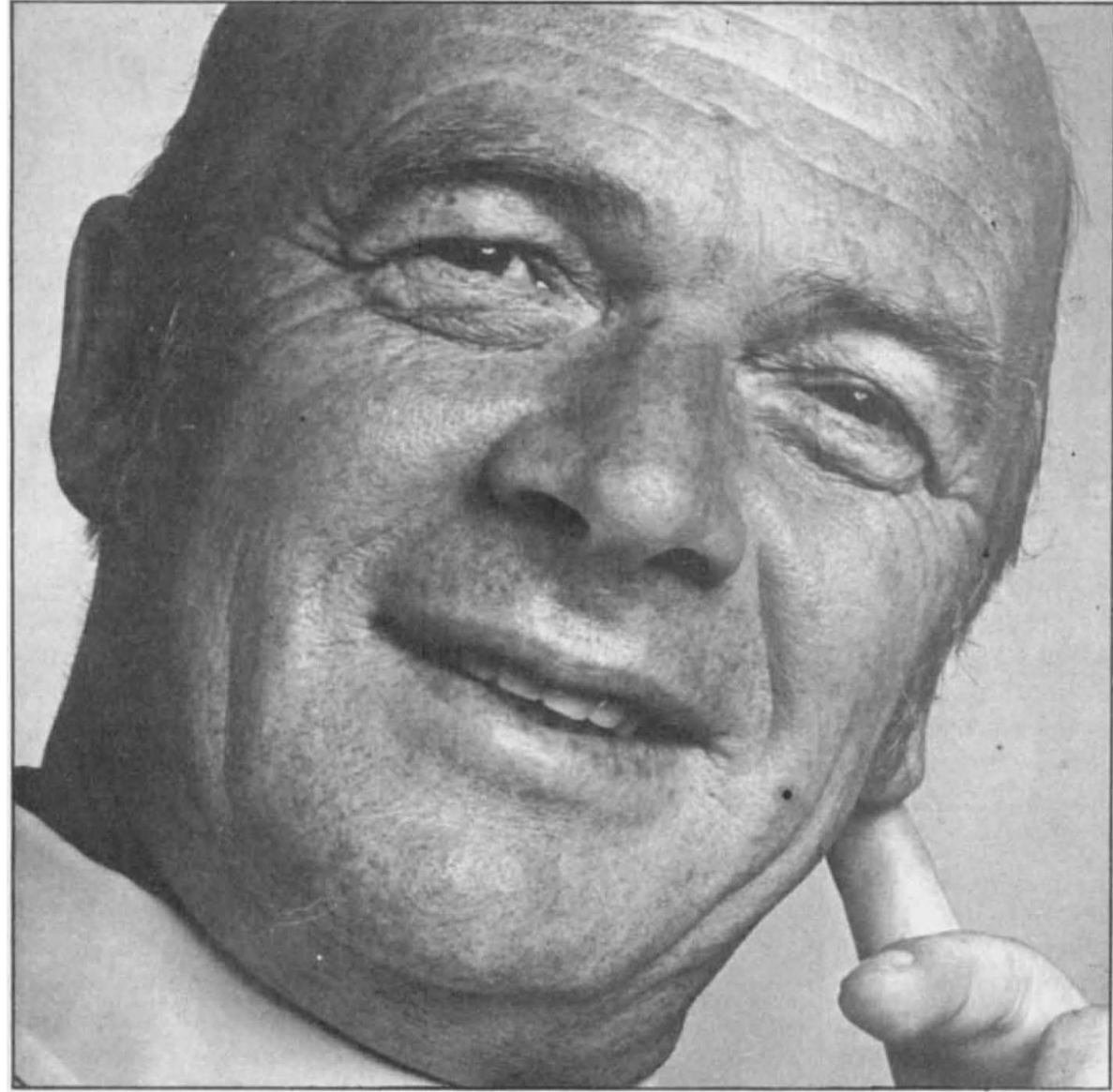

\title{
Open for business
}

Britain's pioneering experiment in mass education, the Open University, has now developed to the point where it seems unlikely that any government will go so far as to close it down. This is a rather modest level of successone would hardly be justified in saying that the Open University has in any sense 'come of age', even though it has produced its first graduates. But there was a real prospect that the incoming Conservative government of 1970 might have abandoned the experiment, and with higher education generally still in a parlous economic state the mere fact of the continued existence of the Open University is something to take note of. How might the bridgehead established by the Open University be used to best advantage in the coming years? And do conventional universities have something to learn from the Open University in terms of cost effectiveness?

\section{-John Gribbin reports.}

THE first lesson that might be learned by some academics is the combination of public relations ability and political awareness which the Open University staff seem to have. It's no secret that in the run up to the 1970 election the Open University's representatives took good care to lobby Margaret Thatcher, then in the Shadow Cabinet, and that this lobbying paid dividends when the Conservative government was elected, against all predictions, later that year. That might seem a wasteful diversion of effort which would, in an ideal world, be better spent on the development of the academic side of the university itself; but without that effort there might not have been a university to develop.

Late in 1974, the Open University revealed to the public gaze an example of its business acumen with the establishment of a consultancy service "to help interested bodies overseas establish similar techniques and systems" to the teaching-at-a-distance $\mathrm{t} \mathrm{c} \mathrm{chniques}$ pioneered by the Open University itself. At that time, Sir Walter Perry, Vice-Chancellor of the Open University, commented that "in four years, the university has shown that distance teaching can be effectively deployed to solve pressing educational problems There is now enough evidence to justify the belief that our experience can be successfully adapted to other environ- ments and to other types of education", Iั and a spokesman for the university stressed that although it has concentrated on teaching to degree level, "the Consultancy Service believes that : similar techniques and systems can be applied to other kinds of education and training, especially life-long learning".

So the university is already looking well beyond the usual narrow confines of higher education establishments. This kind of facility could clearly be of great use in keeping teachers up to date, providing training in the law, or perhaps as a means of welfare and hygiene training. And these developments show clearly how the Open University might be made, if not to pay its own way entirely, at least to contribute substantially to its own running costs. The present marketing activities of the university are far from insignificant, as the table shows, although it must be born in mind that the "margin" mentioned there is not entirely profitthere are other overheads involved in running the marketing operation. The global scale of this marketing operation is also surprising to anyone used to thinking of the Open University as a British establishment; only just over $50 \%$ of present net sales are in the UK.

Perhaps the greatest 'package' success of the Open University in the marketing field is the sale of complete courses to a few American colleges; in these packages books, course unit guides and broadcast material have been sold together and will be used just as they are in the Open University itself. This encourages speculation about the possibility of using modern communications facilities to centralise higher education to a great extent. If students in the USA can take what is in essence an Open University course (even, perhaps, an Open University degree) why should not the same facilities be used by UK universities? There is a powerful case to be made that, other considerations apart, the energy saving implicit in communicating a course to students, rather than transporting students to a course and housing them while they take the course, should alone lead to a major rethinking of our educational system. It is difficult to see that the interests of the country as a whole (or any country) would be less well served if the present scattering of scores of universities across the country were to be replaced by no more than half a dozen establishments organised along the lines of the Open University, perhaps on a regional basis. But that prospect is certainly not one which we are likely to see in the immediate future.

Any movement in that direction is bound to meet opposition from the academic establishment. But it is diffi- 
cult to counter the argument that the Open University approach is simply more efficient at getting its message across to large numbers of people at reasonable cost. The $\mathrm{BBC}$ runs just one studio for Open University programmes, at Alexandra Palace in London, and each television programme takes about one day of studio time to produce. There is also an outside broadcast unit, and radio programmes seem to be produced with hardly any effort at all. With about 50 producers at Alexandra Palace who have some kind of science qualification and this rather shoe-string operation the unit produces programmes which are used for five years before being replaced. And although the initial cost may seem high, the cost per student over that period must compare favourably with the cost per student of conventional lectures, even before account is taken of sales of programmes to other educational establishments.

In addition, for many of the science programmes the demonstrations provided in the Open University programmes are far more elaborate than anything which could be put on, and expected to work, under the restrictions of an ordinary lecture theatre. Again, an experiment which could not be financed by dozens of colleagues separately each academic year is a viable proposition when it only has to be put on once for the benefit of five years' intake of a much larger student body.

Even so, the total cost of the Alexandra Palace operation is not excessive even by the standards of some 'ordinary' universities, and looks even more reasonable when set against typical government expenditure on education and science. The total number of people now working in this BBC department is just over 300 , and in 1973-74 the cost of the operation (wages, transmissions, filming, graphics, scenery, rental, rates, lines, administration, travel, processing and presentation all included) was $£ 2,090,000$. About half of this goes on wages, $£ 600,000$ for the actual manufacture of radio and television programmes (including all repeat fees), $£ 250,000$ for transmitter running costs and some $£ 200,000$ for premises (including lighting, heating and so on).

With a smaller proportion of pupils in secondary schools in Britain now wanting to stay on to take A levels, and fewer of those who qualify at that level wanting to continue their education at university level immediately afterwards, perhaps the time has come to rethink our approach to higher education. The arguments in favour of a break between school and university are well known, and perhaps the Open University approach offers the best route by which

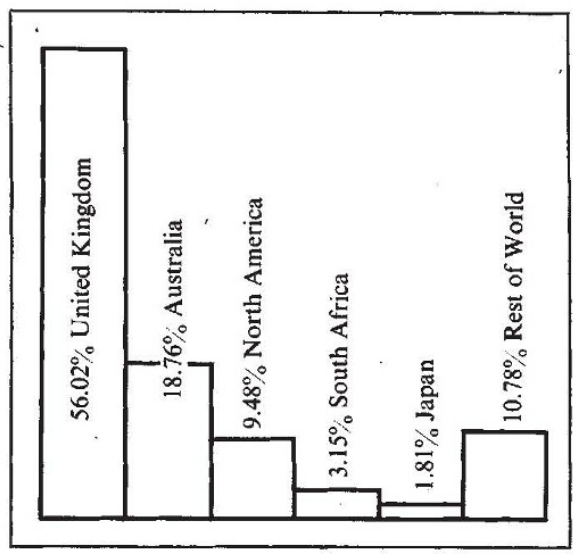

O.U. sales, nine months to Sep, '74.

to return to the academic system for prospective students who had, temporarily at least, had enough of studying and examinations by the time they had reached A-level standard. Without yet going so far as to reduce the number of conventional universities drastically, it does seem that flexibility in combining Open University education with more conventional courses could make the university system as a whole more efficient, both in terms of cost and in terms of providing the greatest flexibility of courses for the greatest number of students.

The longer courses offered by conventional establishments are obvious possibilities for this kind of development; the time is not yet ripe for the Open University to offer a complete medical course (if only because of the difficulties in obtaining practical experience) but is there any real reason why all prospective medical students should not complete a 'remote teaching' pre-medical course before moving on to practical work? It is also difficult to see why law could not prove an ideal course for the Open University treatment, if only the lawyers could be persuaded to move into the last quarter of the twentieth century. And if pre-medical courses are feasible, why not 'pre-university' courses, either as an option or as an essential prerequisite for all students who wish to take degrees? Two years of such study, say, would provide an excellent opportunity both for the prospective degree student to decide if he really does want to return to the academic fold and for the university of his choice to decide if they really want him. It would not be unreasonable for the work involved in such a two-year period of study to count as one third of a degree course, or, following the present Open University practice, for the same workload to be spread over three or four years. Then, the period of residence at traditional university need only be two years, with considerable advantages for the efficient running of those establishments. As most universities that run 'mature student' schemes can report, there would probably be great advantages in terms of a reduction in the drop-out rate and an improvement in academic standards.

There are imperfections in such a scheme, as there are in most, and it would hit hard at some entrenched positions. But with the present problems of the educational system (which have recently led the Secretary of State for Education and Science, Reg Prentice, to order what has been called "an inquiry on the reluctant students") something must not only be done but must be seen to be done. In the absence of other constructive proposals, this possible line of development of the Open University must surely be considered seriously.
Open University marketing:

ANALYSIS OF SALES FOR NINE MONTHS ENDED SEPTEMBER 30, 1974

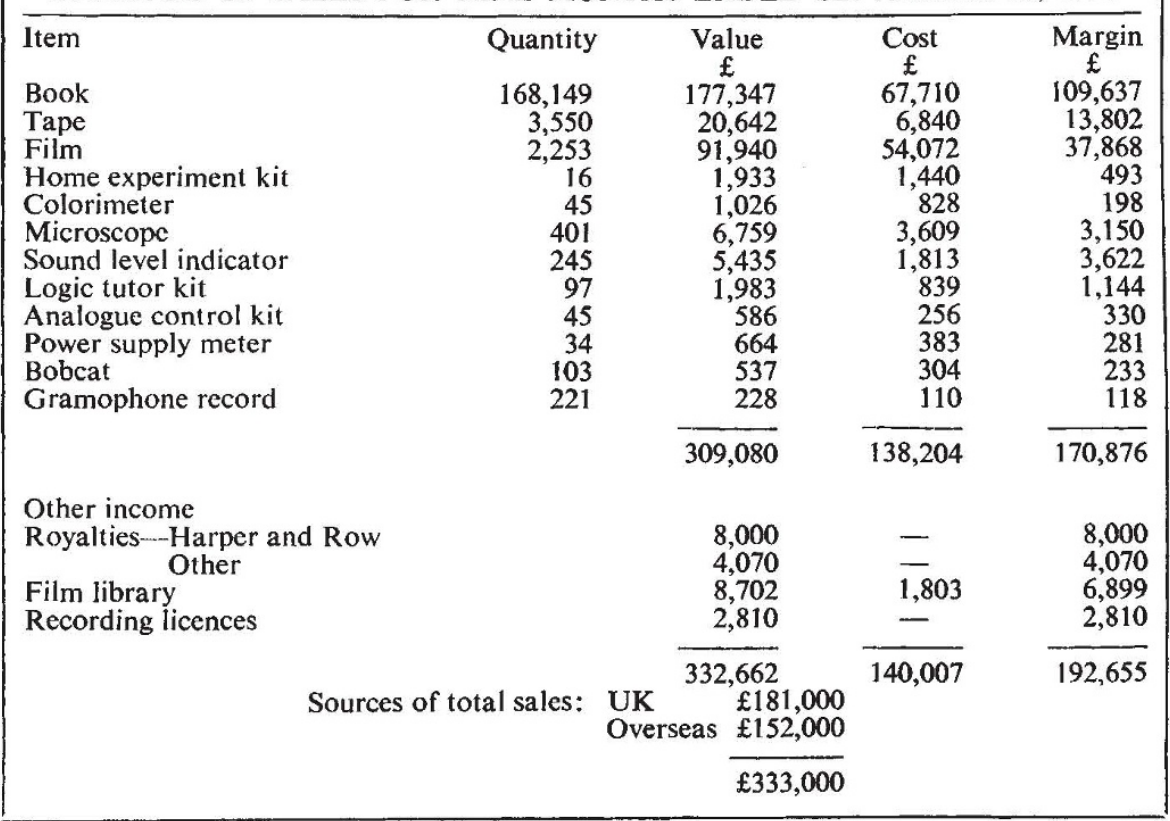

